Article

\title{
Technical and Humanities Students' Perspectives on the Development and Sustainability of Artificial Intelligence (AI)
}

\author{
Vasile Gherheș ${ }^{1, *}$ (1) and Ciprian Obrad 2 (1) \\ 1 Department of Communication and Foreign Languages, Politehnica University of Timișoara, \\ 300006 Timișoara, Romania \\ 2 Department of Sociology, West University of Timișoara, 300223 Timișoara, Romania; ciprian.obrad@e-uvt.ro \\ * Correspondence: vasile.gherhes@upt.ro; Tel.: +40-721-022-440
}

Received: 17 July 2018; Accepted: 24 August 2018; Published: 28 August 2018

check for updates

\begin{abstract}
This study investigates how the development of artificial intelligence (AI) is perceived by the students enrolled in technical and humanistic specializations at two universities in Timisoara. It has an emphasis on identifying their attitudes towards the phenomenon, on the connotations associated with it, and on the possible impact of artificial intelligence on certain areas of the social life. Moreover, the present study reveals the students' perceptions on the sustainability of these changes and developments, and therefore aims to reduce the possible negative impact on consumers, and at anticipate the changes that AI will produce in the future. In order to collect the data, the authors have used a quantitative research method. A questionnaire-based sociological survey was completed by 928 students, with a representation error of only $\pm 3 \%$. The analysis has shown that a great number of respondents have a positive attitude towards the emergence of AI, who believe it will influence society for the better. The results have also underscored underlying differences based on the respondents' type of specialization (humanistic or technical), and their gender.
\end{abstract}

Keywords: artificial intelligence; sustainable development; technology; perceptions

\section{Introduction}

We live in a constantly changing world, marked by profound transformations that are generated by technological advancements, happening at an unprecedented pace. The incredible technological changes taking place every day are also due to the great number of programs carried out by an increasing number of researchers in universities, and various organizations. We are now witnessing. and wondering about the ways in which technology impacts society-such as ways that could lead to sustainable growth in the economy, in culture, and in our life expectancy [1]. We use so much technology daily that we have grown dependent on it. We use it to communicate, to learn, to travel, to do business, etc. Technology has simplified the access to many of the tools needed in the above-mentioned areas of interest.

It has become obvious that the continuous technological evolution is vital to the contemporary society. Nevertheless, it is difficult to quantify the way in which each new technology has affected our lives, and the way in which it is going to influence our future. Although technology solves many problems, it also generates new challenges. Technology impacts our society in a positive and/or negative manner, depending on the way in which it is used. Although it certainly improves our lives, there are also negative side effects that have become more noticeable. Cyberterrorism, malware, mass-collection of personally identifiable information for social manipulation, and addiction to technology (similar to a drug addiction) are only some of the dark sides of the fast-evolving information and communication technology. 
Artificial intelligence (AI) has been studied [2-4] for decades, and is still one of the subjects that captures the imagination of researchers from all walks of life. Covering a vast and nebulous field, whilst being a fashionable subject in big corporations all over the world, AI can be found in applications that filter unwanted e-mails, calculate best routes (by considering the existing traffic information), suggest job offers, or shopping possibilities. Based on powerful computers and algorithms, today's AI impacts almost all areas of human activity. There are a multitude of areas in which AI applications are expected to lead to a sustainable development: Transportation (autonomous electric vehicles, avoiding traffic congestion, etc.), smart agriculture, medicine (monitoring and curing diseases, reducing diagnostic errors, etc.), environmental protection (pollution reduction, resource optimization), constructions (intelligent buildings and green architecture), citizens' safety, etc. There are also perceived risks, such as those related to the development of autonomous weapon systems, replacing human subjects, cyber-attacks, etc. [5-7].

Artificial intelligence refers to the intelligence of machines and that branch of informatics that is working to bring it forth. The term was coined by John McCarthy [8], who also offered a concise definition: "[T]he science and engineering of making intelligent machines"; or "making a machine behave in ways that would be called intelligent if a human were so behaving". The field was created on the idea that human intelligence can be described and defined so precisely that it can be simulated by a computing machine.

Other definitions of the artificial intelligence concept are:

- The Cambridge Dictionary [9]: “[T]he use of computer programs that have some of the qualities of the human mind, such as the ability to understand language, recognize pictures, and learn from experience".

- The American Heritage ${ }^{\circledR}$ Science Dictionary [10]: “The ability of a computer or other machine to perform actions thought to require intelligence. Among these actions are logical deduction and inference, creativity, the ability to make decisions based on past experience or insufficient or conflicting information, and the ability to understand spoken language".

In The Artificial Intelligence Innovation Report of 2016 [11], Deloitte puts forth the following classification regarding AI:

"Artificial Narrow Intelligence (ANI): Sometimes referred to as Weak AI, this is the most limited form of AI and this is what is currently possible in 2016. ANI is capable of carrying out specific tasks brilliantly, using a combination of advanced algorithms, deep learning and various other techniques depending on the use. Often Natural Language processing is employed to facilitate human interaction.

Artificial General Intelligence (AGI): Sometimes referred to as Strong AI or Human-Level AI. At this level, AI would be capable of performing any task to the standard of a human. Precisely when AGI will be achieved is a subject of debate, with most AI specialists predicting it will occur around 2040.

Artificial Superintelligence (ASI): This is an AI that is more advanced than human intelligence. Due to the Law of Accelerating Returns, this state could potentially be realized in mere days of even hours after AGI is achieved. The consequences of developing ASI are, by its very definition, unknown. This level of intelligence would soon be many billion times more intelligent than the smartest human. Because of this, it is impossible for anyone to predict with certainty what this leap in technology will bring forth".

The emergence of AI will change all economic activities; it will create enormous social and economic opportunities, but also major challenges accompanied by ethical dilemmas. Curing cancer, stopping global warming, the disappearance of the human race, eternal life-all of these things are considered possible as AI develops. Researchers in the field foresee a time when robots will become part of our everyday lives as simple appliances, assistants, helpers for certain social categories or assistance for humans carrying out different tasks [12]. 
Some people fear that intelligent computers will replace humans in various activities, and various jobs. In contrast, others believe that the advent of automation and AI will generate new jobs and prosperity.

Since it is an extremely complex field, which only gives rise to speculations about how AI will influence society, there are not many representative studies that might capture people's social perception of AI. For example, the results presented in "Future Progress in Artificial Intelligence: A Survey of Expert Opinion" [13] show that in the opinion of one out of two experts, AI will emerge between 2040 and 2050, whereas nine out of ten believe that the more likely horizon is 2075. In their opinion, superintelligence will be developed in less than 30 years after the emergence of $\mathrm{AI}$, and there are one out of three chances that this development will be "detrimental" or "extremely detrimental" to humanity. Another study, "What Consumers Really Think About AI: A Global Study" [14], carried out in North America, reveals that, while consumers are optimistic about the benefits of AI, they also show fear and confusion regarding the way in which businesses use AI.

In the 2017 Eurobarometer, Attitudes towards the impact of digitization and automation on daily life [15]. Results showed that $52 \%$ of the respondents had not heard, read or seen information about AI over the previous 12 months. On the other hand, $61 \%$ of them claim to have a positive outlook towards robots and AI. The same study reveals that more than two thirds of the respondents $(68 \%)$ agree that robots and artificial intelligence are beneficial to society because they help people in their daily tasks, and that, for $53 \%$ of them, AI does not pose a threat to their jobs, since their activity cannot be carried out by AI.

Furthermore, renowned scientists and businessmen, such as Stephen Hawking, Bill Gates, and Steve Wozniak, (the co-founder of Apple), have expressed their concern at the prospect of a world in which AI exceeds human intelligence. Elon Musk, Tesla co-founder and SpaceX founder, declared on Twitter [16] that "we need to be super careful with AI because it is potentially more dangerous that nukes". Google expert, Ray Kurzweil [17], claims that biological humans need not fear artificial intelligence, as it will enhance us the more we use it.

The accelerated development of $\mathrm{AI}$ in recent years is closely linked to other modern concepts (machine learning, neutral networks). Machine Learning (ML) is already present in numerous products. Both ML and AI are increasingly based upon advanced data analytics methods that extract value from large data sets, also called "Big Data" $[18,19]$.

The AI phenomenon has also been studied from a multidisciplinary perspective [20]. More and more numerous models and applications based on new technologies, such as augmented virtual reality, Internet of Things, 5G networks, anticipative computers, etc., have been presented lately. The new era in which we live is characterized by the Data-Knowledge-Wisdom Ecosystem, where knowledge artifacts and human and social entities will interact through new business models and applications [21].

In 2015, the United Nations published 17 Sustainable Development Goals (SDGs) as a roadmap to ensure a sustainable future by 2030. On this issue, in October 2017, at a joint meeting of the United Nations General Assembly Second Committee and Economic and Social Council (ECOSOC), discussing the topic: "The Future of Everything-Sustainable Development in the Age of Rapid Technological Change", Stephen Ibaraki presented the way in which IA and machine learning technologies will dramatically change the world we live in. Stephen Ibaraki [22] suggests that AI innovation will be central to the achievement of the United Nations' SDGs and help to solve humanity's grand challenges, capitalizing on the unprecedented quantities of data now being generated on human health, commerce, communications, transportation, migration and more. AI can play a role in addressing each of the UN SDGs.

In order for these goals to be attained, a favorable perception regarding AI, and its sustainable development, should first and foremost exist. In other words, people should accommodate AI into their lives. At the moment, as far as we know, in Romania no study on the population's attitude towards artificial intelligence has been carried out to assess whether their attitude is positive or negative, and what impact artificial intelligence will have on society. This study aims at evincing the attitudes of 
the students enrolled at two universities in Timisoara towards the emergence of artificial intelligence and its influence on our lives in the future.

\section{Research Methodology}

One of the main parts of our study, AI sustainable development, was researched in detail by means of five indicators: (1) The perception on the increase in the humankind comfort level, (2) the perception on the improvement in healthcare and human health, (3) the perception on the increase in social equity, (4) the perception on the optimization of material resources, and (5) the perception on the decrease in pollution. These indicators were included in a work tool specific to a quantitative research method (social survey through questionnaire).

The design of the work tool started from some research questions:

- Does the study population have enough information to be aware of the AI concept and of its applications?

- What are the students' attitudes towards the emergence and the development of AI?

- What is their opinion regarding the sustainability of the changes that AI development will bring in the future?

- In what way do the specializations the respondents pursue (technical and humanities) trigger different attitudes regarding AI?

Before applying the questionnaire, various meetings with the students took place. The students were explained the research intentions and were requested to participate in the study. The respondents are students in first, second, and third years of undergraduate study programs. The instrument we used was an anonymous online questionnaire, posted on the Isondaje.ro platform (which is an online surveys service). We chose the option of filling out the questionnaire online since this approach is quicker, cheaper, and gives instant access to the database. In order to satisfy the demanding requirement of having a representative sample for the study population, the choice of the respondents was controlled based on the study program type (humanities $-50.5 \%$, and technical studies $-49.5 \%$ ), and on relatively equal percentages for gender ( $48.2 \%$ males, and $51.8 \%$ females). The data were collected between 5 March and 26 April 2018, based on the answers of 928 students of the existing universities in Timișoara, students in first, second, and third years of undergraduate study programs, the margin of error being of $3.2 \%$. The target population was selected for two reasons. Firstly, it is an educated population that is well-informed about the topic of the present study. Secondly, the selected target population will be the active population category on which the AI development will have a greater impact in the future. The questionnaires was given to students from technical specializations in these universities, as well as students from humanities specializations (technical studies-humanistic studies), which is one of the variables on which we based our later analyses. The respondents' age distribution shows that the average age is of 20.69 years old, the lowest registered value being of 19 years old and the highest, of 50 years old, the most frequent category being that of 19 years old.

Our objectives were:

1. To identify how well informed the students were, and how they understood the concept of artificial intelligence.

2. To pinpoint the respondents' attitudes towards artificial intelligence, and the connotations that the subject has acquired lately.

3. To determine the respondents' attitude towards the emergence, and development of artificial intelligence.

4. To capture the impact that the development of artificial intelligence may have on different areas of the social life.

The research hypotheses that have been put forward were as follows: 
Hypothesis 1 (H1). Students pursuing technical studies have a higher level of information regarding AI use than those pursuing humanities studies.

Hypothesis 2 (H2). Male students have a different level of information regarding AI use than female students.

Hypothesis 3 (H3). Students pursuing technical studies have a more favorable perception regarding the sustainability of the AI development than humanities students.

\section{Results}

A first perspective we looked at in our study was to identify how well the respondents understood the concept of artificial intelligence. Our results show that $84.6 \%$ consider that they know what artificial intelligence means, whereas $12 \%$ claim that they do not know what the concept means. At the same time, 3.4\% answered "I don't know/I won't answer". There are no significant differences between the categories of respondents based on the type of their undergraduate specialization, with the exception of those who do not know what the notion of artificial intelligence means. In this case, those respondents studying humanities register a score of $17.2 \%$, whereas the respondents in technical studies register a score of just $6.8 \%$ (see Table 1). Based on the gender variable the following differences ensue: $95.5 \%$ of the male respondents and $75.8 \%$ of the female ones claim to know what artificial intelligence is. According to the same variable, there are differences in the case of those students who claim not to know what this concept means: $3.3 \%$ of them are male, while $19.1 \%$ are female.

Table 1. Knowing the meaning of AI by studies.

\begin{tabular}{ccccc}
\hline & & Technical & Humanistic & Total \\
\hline \multirow{2}{*}{$\begin{array}{c}\text { Do you know what artificial } \\
\text { intelligence means? }\end{array}$} & Yes & $90.0 \%$ & $79.1 \%$ & $84.6 \%$ \\
& I don't know, I won't answer & $6.8 \%$ & $17.2 \%$ & $12.0 \%$ \\
\hline \multicolumn{2}{c}{ Total } & $3.2 \%$ & $3.7 \%$ & $3.4 \%$ \\
\hline
\end{tabular}

In connection to how well informed the respondents were about artificial intelligence, as you can see in Figure 1, the highest percentage belongs to the category of those who believe that they have an average awareness of artificial intelligence (36.1\%). By referring to this average category, while cumulating two other answers (very well informed, $2.4 \%$, and well informed, $16.8 \%$ ), which represent the number of those with an above-average level of awareness, as well as cumulating the remaining two answers (poorly informed, 35\%, and very poorly informed, 9.7\%) which represent the category of those with a below-average level of awareness, showing that the number of those who consider themselves less informed is greater than the category of those who believe that they are well informed on the subject ( $44.7 \%$ as opposed to $19.2 \%)$. 


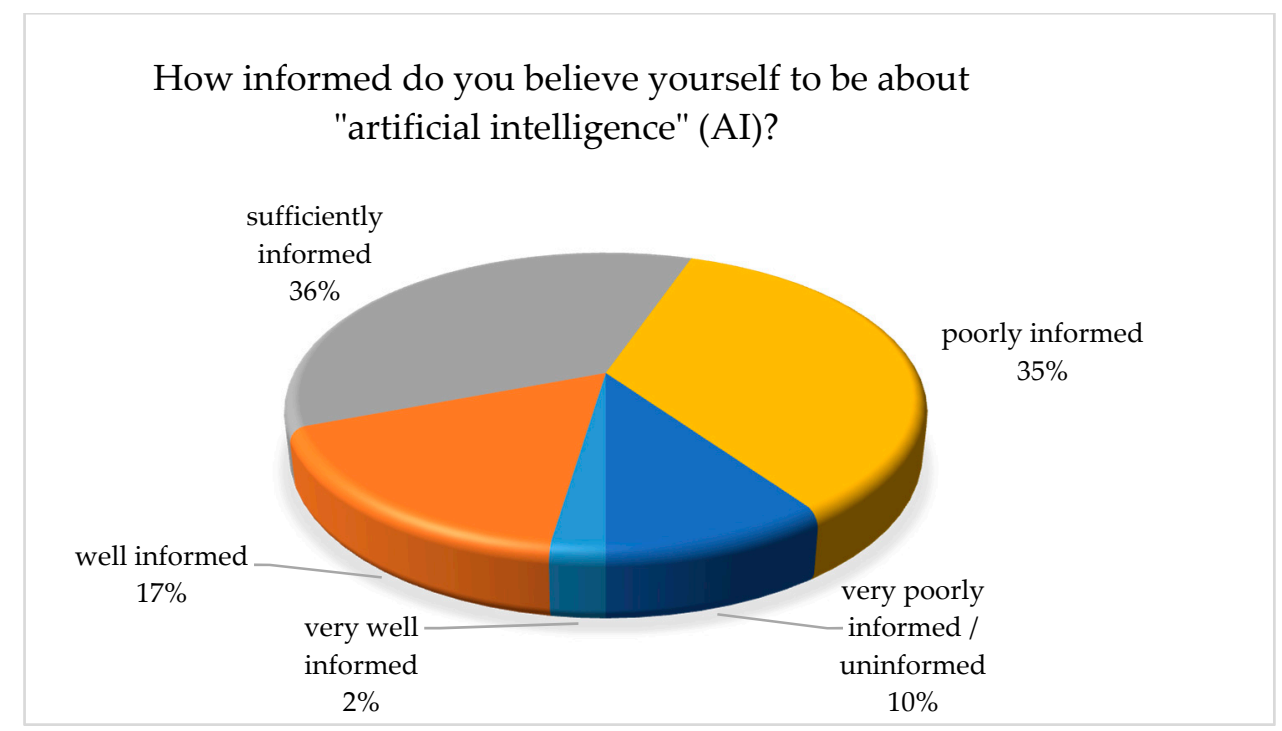

Figure 1. Level of information.

In this case, there are differences in accordance with the type of undergraduate specialization the students pursue, where those who consider themselves sufficiently informed about artificial intelligence register the greatest disproportions. Students from technical specializations score a percentage of $23.7 \%$ whereas those studying humanities scored only $9.8 \%$.

The above-mentioned first research hypothesis (H1) stipulates the idea of a discrepancy in terms of the level of information between the students pursuing the two different specializations. After testing this hypothesis with the t-test, we have obtained the following results: The $p$-value of Levene's test is $>0.05$ and $\mathrm{F}=0.360$. This tells us that we should look at the first line "Equal variances assumed" row for the $t$-test (and corresponding confidence interval) results (Table 2).

Table 2. Independent samples test for $\mathrm{H} 1$.

\begin{tabular}{ccccccccc}
\hline & & \multicolumn{3}{c}{$\begin{array}{c}\text { Levene's Test for } \\
\text { Equality of Variances }\end{array}$} & \multicolumn{5}{c}{$t$-Test for Equality of Means } \\
\cline { 2 - 8 } & & F & Sig. & $t$ & Df & Sig. (2-Tailed) & Mean Difference \\
\hline $\begin{array}{c}\text { Level of } \\
\text { information } \\
\text { about AI }\end{array}$ & $\begin{array}{c}\text { Equal } \\
\text { variances assumed }\end{array}$ & 0.360 & 0.549 & 6.639 & 925 & 0.000 & 0.403 \\
\cline { 2 - 8 } & $\begin{array}{c}\text { Equal variances } \\
\text { not assumed }\end{array}$ & & & 6.641 & 925.000 & 0.000 & 0.403 \\
\hline
\end{tabular}

Based on the results, we can state that there was a significant difference in the level of information regarding AI between technical students and humanities students ( $\mathrm{t} 925=6639, p<0.01)$.

Significant differences between the two groups can be observed, the students pursuing technical studies having higher values for the level of information $(m=2.87)$ compared to the humanities students group $(\mathrm{m}=2.47)$. The data distribution is normal and, as it can be seen in the comparative analysis, the differences are sufficiently clear and cannot appear randomly, the influence of chance being below $1 \%$ of the cases $(p<0.01)$.

The gender variable also influences this question leading us to conclude that male respondents are better informed on the subject than female respondents (Table 3). 
Table 3. Level of information by gender.

\begin{tabular}{|c|c|c|c|c|}
\hline & & Male & Female & Total \\
\hline \multirow{5}{*}{$\begin{array}{l}\text { How informed do you believe yourself to } \\
\text { be about "artificial intelligence"? }\end{array}$} & very well informed & $4.3 \%$ & $0.8 \%$ & $2.4 \%$ \\
\hline & well informed & $23.6 \%$ & $11.2 \%$ & $16.8 \%$ \\
\hline & sufficiently informed & $41.3 \%$ & $31.9 \%$ & $36.1 \%$ \\
\hline & poorly informed & $27.0 \%$ & $41.7 \%$ & $35.1 \%$ \\
\hline & Very poorly informed/uninformed & $3.8 \%$ & $14.4 \%$ & $9.6 \%$ \\
\hline \multicolumn{2}{|l|}{ Total } & $100.0 \%$ & $100.0 \%$ & $100.0 \%$ \\
\hline
\end{tabular}

H2 hypothesis-Male students have a different level of information as compared to female students-was tested in the same manner using the $t$-test (Table 4).

Table 4. Independent samples test for $\mathrm{H} 2$.

\begin{tabular}{cccccccc}
\hline & & \multicolumn{2}{c}{$\begin{array}{c}\text { Levene's Test for } \\
\text { Equality of Variances }\end{array}$} & & \multicolumn{2}{c}{$t$-Test for Equality of Means } \\
\cline { 2 - 8 } & F & Sig. & $t$ & df & Sig. (2-Tailed) & Mean Difference \\
\hline $\begin{array}{c}\text { Level of } \\
\text { information } \\
\text { about AI }\end{array}$ & $\begin{array}{c}\text { Equal } \\
\text { variances assumed }\end{array}$ & 5.700 & 0.017 & 9.269 & 925 & 0.000 & 0.553 \\
\cline { 2 - 8 } & $\begin{array}{c}\text { Equal variances } \\
\text { not assumed }\end{array}$ & & 9.254 & 886.056 & 0.000 & 0.553 \\
\hline
\end{tabular}

The $p$-value of Levene's test is $<0.05$ and $\mathrm{F}=5.700$. This tells us that we should look at the second line "Equal variances not assumed" row for the $t$-test (and corresponding confidence interval) results. Based on these results, we can state that there was a significant difference in the level of information regarding AI between male and female students ( $\mathrm{t} 886.056=9.254, p<0.01)$. When they hear the phrase "artificial intelligence", most participants (42\%) think about robots. A second category thinks about computers (35\%), whereas a third envisions science $(19.6 \%)$. There are no differences based on gender and specialization type.

Most respondents (36\%) claim that they heard discussions about artificial intelligence this week. Next category consists of those who have heard discussions about artificial intelligence over the past few months (23\%). Then come those who have heard talks about artificial intelligence this last month $(21.9 \%)$. The past year (9.7\%) and more than a year ago $(9.5 \%)$ are the last two categories of answers. In this case we can notice a tendency for students in technical specializations to be more informed about artificial intelligence than those students who study humanities. For example, $44.9 \%$ of students in technical studies answered this week, in contrast to $27 \%$ of students in humanities. At the opposite end of the spectrum, the percentage of those who answered the past year is higher among respondents studying humanities (14.2\% as opposed to $5.1 \%$ ). The gender variable also influences the answers to these questions, with $47.2 \%$ of the male students answering this week as compared with $26.7 \%$ of the female students. We could conclude that the profile of the student who has heard more frequent talks about artificial intelligence is male and pursuing a technical specialization.

While $46.8 \%$ of the students thought that the manner in which the information about artificial intelligence was presented to them was neutral, $46.3 \%$ of them considered that the information was positive. Only $6.9 \%$ considered that the manner in which they received the information was negative. The gender differences and the type of specialization are displayed in the tables below (see Tables 5 and 6). They show that, in the case of the male respondents in technical specializations, the frequency of positive information is higher. 
Table 5. The manner in which the information about artificial intelligence was presented by studies.

\begin{tabular}{ccccc}
\hline & & Technical Studies & Humanistic Studies & Total \\
\hline \multirow{2}{*}{ How was the information about } & negatively & $4.5 \%$ & $9.2 \%$ & $6.8 \%$ \\
artificial intelligence presented? & neutrally & $37.3 \%$ & $56.6 \%$ & $46.9 \%$ \\
& positively & $58.2 \%$ & $34.2 \%$ & $46.3 \%$ \\
\hline Total & & $100.0 \%$ & $100.0 \%$ & $100.0 \%$ \\
\hline
\end{tabular}

Table 6. The manner in which the information about artificial intelligence was presented by studies.

\begin{tabular}{ccccc}
\hline & & Male & Female & Total \\
\hline \multirow{2}{*}{ How was the information about } & negatively & $6.0 \%$ & $7.5 \%$ & $6.8 \%$ \\
artificial intelligence presented? & neutrally & $37.9 \%$ & $54.2 \%$ & $46.9 \%$ \\
& positively & $56.1 \%$ & $38.3 \%$ & $46.3 \%$ \\
\hline Total & & $100.0 \%$ & $100.0 \%$ & $100.0 \%$ \\
\hline
\end{tabular}

In the opinion of approximately a third of the respondents, the accelerated development of artificial intelligence is neither good nor bad. We take this attitude as being the average towards the phenomenon we are analyzing. Cumulatively, the answers for the variants a very good thing $(18.2 \%)$ and a rather good thing $(28.1 \%)$ score $46.3 \%$; therefore, we can conclude that the respondents exhibit a rather positive attitude towards artificial intelligence. The opinion of those who believe that artificial intelligence is a rather bad thing or a bad thing cumulates $12.5 \%$, and $2.5 \%$ of the answers, respectively. The variables of gender and specialization influence the answers, as presented in Tables 7 and 8 .

Table 7. The perception of the development of artificial intelligence by gender.

\begin{tabular}{|c|c|c|c|c|}
\hline & & Male & Female & Total \\
\hline \multirow{3}{*}{$\begin{array}{l}\text { In your opinion, the accelerated } \\
\text { development of artificial intelligence is: }\end{array}$} & a very good thing & $24.6 \%$ & $13.0 \%$ & $18.2 \%$ \\
\hline & a rather good thing & $34.1 \%$ & $23.2 \%$ & $28.1 \%$ \\
\hline & neither good nor bad & $23.9 \%$ & $43.2 \%$ & $34.5 \%$ \\
\hline
\end{tabular}

Table 8. The perception of the development of artificial intelligence by studies.

\begin{tabular}{ccccc}
\hline & & Technical Studies & Humanistic Studies & Total \\
\hline \multirow{2}{*}{ In your opinion, the accelerated } & a very good thing & $23.5 \%$ & $12.9 \%$ & $18.2 \%$ \\
development of artificial intelligence is: & a rather good thing & $32.6 \%$ & $23.5 \%$ & $28.1 \%$ \\
& neither good nor bad & $28.1 \%$ & $41.0 \%$ & $34.5 \%$ \\
\hline
\end{tabular}

For more than half of the respondents, $52.7 \%$ to be exact, the perspective of the artificial intelligence's accelerated development does not represent a reason for concern. There is also a category of respondents who claim to be alarmed by the phenomenon, a share of $35 \%$, to which we can add the category of those who are undecided, representing $12.3 \%$ (see Figure 2). 
Are you concerned about the rapid development of artifcial intelligence?

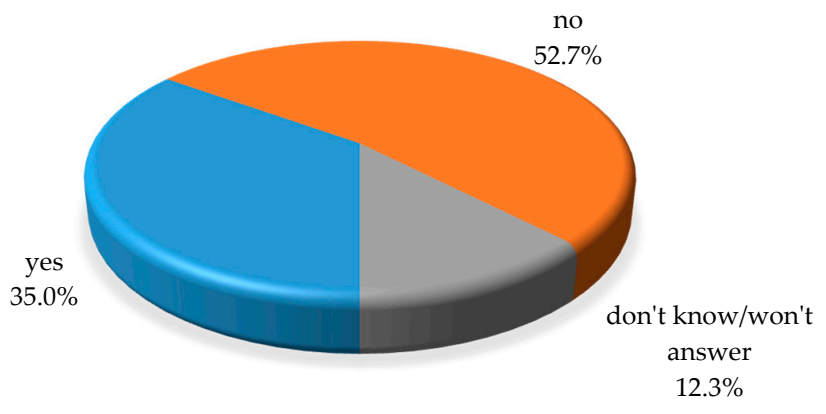

Figure 2. Concerns about the rapid development of AI.

From the point of view of the respondents' gender, we notice that there are significant differences between the two categories. Namely, male students are less concerned about the development of artificial intelligence, this attitude scoring $65.2 \%$, in comparison with the female population where this category of answers scored $42 \%$. The distribution of answers by male students is off-balance, $65.2 \%$ answered no to the question above, whereas only $26.5 \%$ answered yes. In the case of female respondents, the distribution is more even between the respondents who claim to be worried about the phenomenon, about $42 \%$ for each category. A situation similar to that of male students is present in the case of the students who follow a technical specialization, with relatively equal differences within the same category, whereas in the case of the students who study humanities there is a more uniform distribution of answers.

In close connection to the previous question was the following one: "Do you believe that the development of artificial intelligence will have a positive influence on society?" The distribution of answers (Figure 3) clearly shows that most respondents believe this development will have a positive impact on the evolution of society.

Do you believe that the development of artificial intelligence will have a positive influence on society?

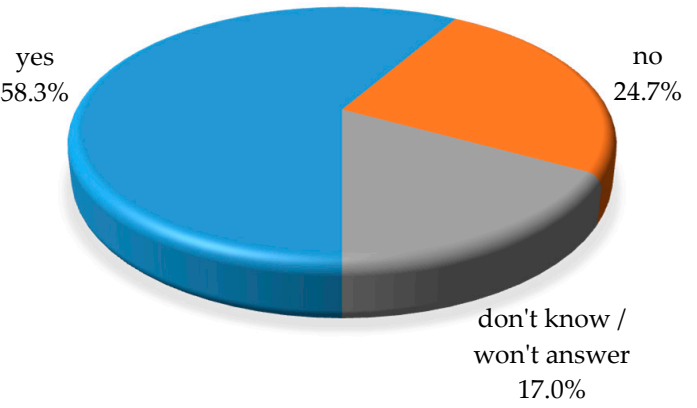

Figure 3. AI positive influence on society.

As you can see in Table 9, there are again differences between positive and negative opinions based on the respondents' gender. Both categories manifest a generally positive attitude towards how the development of artificial intelligence is going to influence society $(66.8 \%$ of the male respondents, 
$51.5 \%$ of the female respondents). Just like in the case of the previous questions, we can identify of greater optimism among male students as opposed to female students. The distribution according to the type of specialization is also somewhat identical, the answers being registered in Table 10.

Table 9. AI positive influence on society by gender.

\begin{tabular}{ccccc}
\hline & & Male & Female & Total \\
\hline $\begin{array}{c}\text { Do you believe that the development } \\
\text { of artificial intelligence will have a }\end{array}$ & yes & $66.8 \%$ & $51.5 \%$ & $584 \%$ \\
positive influence on society? & no & $18.9 \%$ & $29.5 \%$ & $24.7 \%$ \\
\hline Total & & $14.3 \%$ & $19.1 \%$ & $16.9 \%$ \\
\hline
\end{tabular}

Table 10. AI positive influence on society by studies.

\begin{tabular}{rcccc}
\hline & & Technical Studies & Humanistic Studies & Total \\
\hline $\begin{aligned} \text { Do you believe that the development } \\
\text { of artificial intelligence will have a }\end{aligned}$ & yes & $64.2 \%$ & $52.5 \%$ & $58.4 \%$ \\
positive influence on society? & no & $18.6 \%$ & $30.9 \%$ & $24.7 \%$ \\
\hline Total & & $17.3 \%$ & $16.6 \%$ & $16.9 \%$ \\
\hline
\end{tabular}

An important aspect of the present research is the perception on the contribution of the AI to the sustainable development of some areas of the social life in the future. Therefore, for more than two thirds of the respondents, the immediate impact of the AI development would be on the automation of everyday human activities in terms of simplification and efficiency. Thus, it would increase the safety of citizens, reduce the risk of accidents in all areas of human activity, and eliminate errors. Another benefit brought to humankind by the development of $\mathrm{AI}$ and mentioned by over half of the subjects included in the study is identified in the medical field, where the viable contributions AI can bring are: Fighting or eradicating certain infectious diseases, curing cancer, diagnosing health problems in a much faster and more accurate way, robot-assisted surgery, and so on. Agriculture can also be developed sustainably with the help of AI, according to one third of the participants in the study. Their responses include aspects such as increasing the agricultural production, pest control, automating the cultivation and harvesting processes, optimizing resources according to the actual crop needs, all of which lead to combating hunger and reducing poverty. Sustainability in construction is another advantage identified by the students included in the study. In this respect, the respondents' responses emphasize resource management activities available with low environmental impact, energy conservation, building sustainability, and the like. Other benefits that underpin the idea of sustainable development through the contribution of AI forms are: Social assistance for people with special needs, high speed of data processing, record-breaking information transmission, human capacity development, optimization of economic activities by reducing production costs, and last but not least, the accelerated evolution of technology.

Will artificial intelligence destroy humanity, or not? At the moment, numerous teams of researchers and programmers are working in order to optimize artificial intelligence. However, there are many skeptics who warn that once artificial intelligence becomes self-aware, robots and intelligent machines could turn on their human makers.

As you can see in the Figure 4, by cumulating the answer variants high and very high, most respondents seem to think that the scenario in which artificial intelligence machines will destroy humanity is likely, as opposed to those who do not believe this is likely to happen (by cumulating the answers low and very low). At the same time, you can notice that there is a relatively large category of respondents who believe that the probability for an apocalyptic scenario is neither great nor small (29.2\%). 
What do you think is the probability that artificial intelligence machines will destroy humanity?

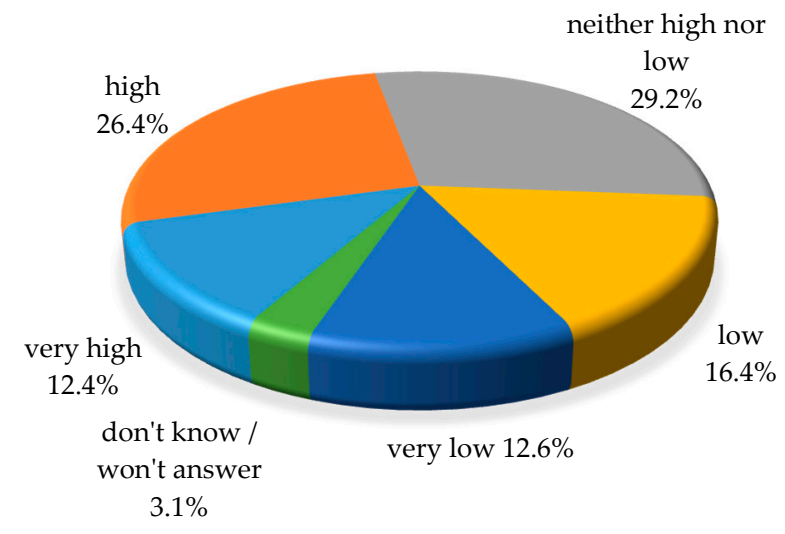

Figure 4. The probability that AI machines will destroy humanity.

As far as the distribution of answers based on gender is concerned, you can notice a difference between female and male respondents, with the former believing that the probability for intelligent machines to destroy humanity is high, as opposed to the latter (Table 11). The differences stemming from the type of specialization are not that significant. Nevertheless, students in humanities show a greater fear at the idea that intelligent machines will destroy humanity, in comparison to those in technical specializations.

Table 11. The probability that AI machines will destroy humanity by gender.

\begin{tabular}{ccccc}
\hline & & Male & Female & Total \\
\hline What do you think is the probability & very high & $8.4 \%$ & $15.5 \%$ & $12.3 \%$ \\
that artificial intelligence machines & high & $22.7 \%$ & $29.5 \%$ & $26.4 \%$ \\
will destroy humanity? & neither high nor low & $28.9 \%$ & $29.5 \%$ & $29.2 \%$ \\
\hline
\end{tabular}

As stated in the introduction, we are very likely to come across positive, negative, or neutral attitudes towards the development of technology, and in our case, towards artificial intelligence. Therefore, in order to identify the respondents' feelings towards the development of artificial intelligence, we introduced a question with a set of answers from which to elicit this attitude. Feelings such as concern, confusion/uncertainty, indifference, optimism, and enthusiasm were introduced in the questionnaire, and we asked our respondents to select which ones characterize their feelings best (multiple answer, each respondent having the possibility to select one or more answer variants). As you can see in Figure 5, optimistic answers represent the largest category (28.3\%), followed by answers which betray confusion (26.9\%). Thus, we have two categories with polarized points of view. We noticed that the category of confused respondents is relatively larger than that of the optimists and the enthusiasts. 
How does thinking about what might happen in the future due to the development of artificial intelligence make you feel?

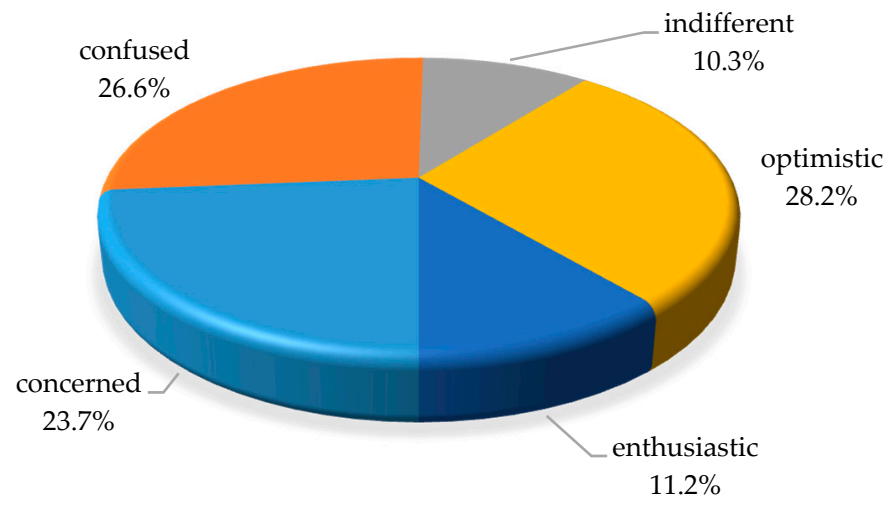

Figure 5. Feelings about the development of AI.

Table 12 consists of the distribution of answers to the question How does thinking about what might happen in the future due to the development of artificial intelligence make you feel? in association with the participants' gender and specialization (for the answer options concerned, confused, indifferent, optimistic, and enthusiastic). Based on the respondents' gender, the biggest differences occurred among those considering themselves to be optimistic, $45.3 \%$ of them being male, $20 \%$ more than the answers given by female students (25.3\%). A smaller difference between the genders were registered for the enthusiastic answer variant, male respondents again scoring higher than female respondents, but by only $15.5 \%$. Taking into account the type of specialization, the biggest differences occurred again for the optimistic answer variant as those students pursuing technical studies are $17.1 \%$ more optimistic than those studying humanities.

Table 12. Feelings about the development of AI by gender and studies.

\begin{tabular}{rcccccc}
\hline \multirow{2}{*}{} & & \multicolumn{2}{c}{ Gender } & \multicolumn{2}{c}{ Studies } & \multirow{2}{*}{ Total } \\
\cline { 3 - 6 } Concerned & Mo & $79.5 \%$ & $64.4 \%$ & $76.5 \%$ & $65.8 \%$ & $71.2 \%$ \\
& Yes & $20.5 \%$ & $35.6 \%$ & $23.5 \%$ & $34.2 \%$ & $28.8 \%$ \\
\hline \multirow{2}{*}{ Total } & & $100.0 \%$ & $100.0 \%$ & $100.0 \%$ & $100.0 \%$ & $100.0 \%$ \\
\hline \multirow{2}{*}{ Confused } & No & $79.5 \%$ & $64.4 \%$ & $72.7 \%$ & $62.3 \%$ & $67.6 \%$ \\
& Yes & $20.5 \%$ & $35.6 \%$ & $27.3 \%$ & $37.7 \%$ & $32.4 \%$ \\
\hline \multirow{2}{*}{ Total } & & $100.0 \%$ & $100.0 \%$ & $100.0 \%$ & $100.0 \%$ & $100.0 \%$ \\
\hline \multirow{2}{*}{ indifferent } & No & $85.7 \%$ & $88.8 \%$ & $87.2 \%$ & $87.6 \%$ & $87.4 \%$ \\
& Yes & $14.3 \%$ & $11.2 \%$ & $12.8 \%$ & $12.4 \%$ & $12.6 \%$ \\
\hline \multirow{2}{*}{ Total } & & $100.0 \%$ & $100.0 \%$ & $100.0 \%$ & $100.0 \%$ & $100.0 \%$ \\
\hline \multirow{2}{*}{ Optimistic } & No & $54.7 \%$ & $74.7 \%$ & $56.9 \%$ & $74.5 \%$ & $65.6 \%$ \\
& Yes & $45.3 \%$ & $25.3 \%$ & $43.1 \%$ & $25.5 \%$ & $34.4 \%$ \\
\hline \multirow{2}{*}{ Total } & & $100.0 \%$ & $100.0 \%$ & $100.0 \%$ & $100.0 \%$ & $100.0 \%$ \\
\hline \multirow{2}{*}{ enthusiastic } & no & $77.8 \%$ & $93.3 \%$ & $82.1 \%$ & $90.6 \%$ & $86.3 \%$ \\
& yes & $22.2 \%$ & $6.7 \%$ & $17.9 \%$ & $9.4 \%$ & $13.7 \%$ \\
\hline \multirow{2}{*}{ Total } & & $100.0 \%$ & $100.0 \%$ & $100.0 \%$ & $100.0 \%$ & $100.0 \%$ \\
\hline
\end{tabular}


The disappearance of jobs is considered to be one of the threats posed by the development of AI [23], the fear being that human activity might be displaced by AI. In order to pinpoint the respondents' opinion towards this issue we introduced the following query in the questionnaire: Do you agree with artificial intelligence replacing humans in certain activities and jobs? The results show that most participants in the study (36.3\%) agree entirely. The following category with relatively similar results is the one in total disagreement $(33.2 \%)$. What we are seeing is a polarization of opinions to which we can add those who consider themselves indifferent to the statement (21.4\%). The undecided ones represent $9.1 \%$ of the answers.

As you can see in Tables 13 and 14, there are significant differences between the answers given by the male and female respondents to this question. The differences also persist in the case of the two types of specializations: The respondents who study technical subjects are more likely to accept the idea that artificial intelligence might replace people in certain jobs and activities in the future.

Table 13. Replacing the humans in activities and jobs by gender.

\begin{tabular}{ccccc}
\hline & & Male & Female & Total \\
\hline \multirow{3}{*}{$\begin{array}{c}\text { I agree with artificial intelligence replacing } \\
\text { humans in certain activities and jobs }\end{array}$} & Totally agree & $48.9 \%$ & $25.9 \%$ & $36.3 \%$ \\
& Indifferent & $23.6 \%$ & $19.4 \%$ & $21.3 \%$ \\
& Totally disagree & $19.8 \%$ & $44.2 \%$ & $33.2 \%$ \\
& Don't know/won't answer & $7.6 \%$ & $10.4 \%$ & $9.2 \%$ \\
\hline Total & & $100.0 \%$ & $100.0 \%$ & $100.0 \%$ \\
\hline
\end{tabular}

Table 14. Replacing the humans in activities and jobs by studies.

\begin{tabular}{ccccc}
\hline & & Technical & Humanistic & Total \\
\hline \multirow{3}{*}{$\begin{array}{c}\text { I agree with artificial intelligence replacing } \\
\text { humans in certain activities and jobs }\end{array}$} & Totally agree & $45.6 \%$ & $26.8 \%$ & $36.3 \%$ \\
& Indifferent & $22.8 \%$ & $19.8 \%$ & $21.3 \%$ \\
& Totally disagree & $22.6 \%$ & $44.0 \%$ & $33.2 \%$ \\
& Don't know/won't answer & $9.0 \%$ & $9.4 \%$ & $9.2 \%$ \\
\hline Total & & $100.0 \%$ & $100.0 \%$ & $100.0 \%$ \\
\hline
\end{tabular}

The domains of activity in which more than half of the respondents believe that artificial intelligence will be far more superior to humans are, in descending order: The automotive industry $(83 \%)$, agriculture $(66.6 \%)$, banking $(64.3 \%)$, package delivery and courier services $(56.3 \%)$, public transport $(51.5 \%)$, the military (51.3\%), and firefighting (51.3\%). At the opposite end, where AI is less likely to outsmart humans, we find: Education (23.5\%), artistic creativity $(24.8 \%)$, citizens' safety $(31.8 \%)$, and medicine/surgery (36\%). The two main variables in the study (gender and type of specialization) did not register any significant deviations from the average value obtained for each answer variant.

With regard to autonomous cars, which is quite a popular debate topic nowadays, the respondents' attitude is generally favorable. Only $27 \%$ (Figure 6) stated that they do not trust this technology (mean resulting from cumulating all existing unfavorable opinions towards the subject of our research). There are no differences generated by the respondents' gender and type of specialization. 
To what degree would you accept that your family drive an autonomous car if you knew that their accident rates are far lower than those of human drivers?

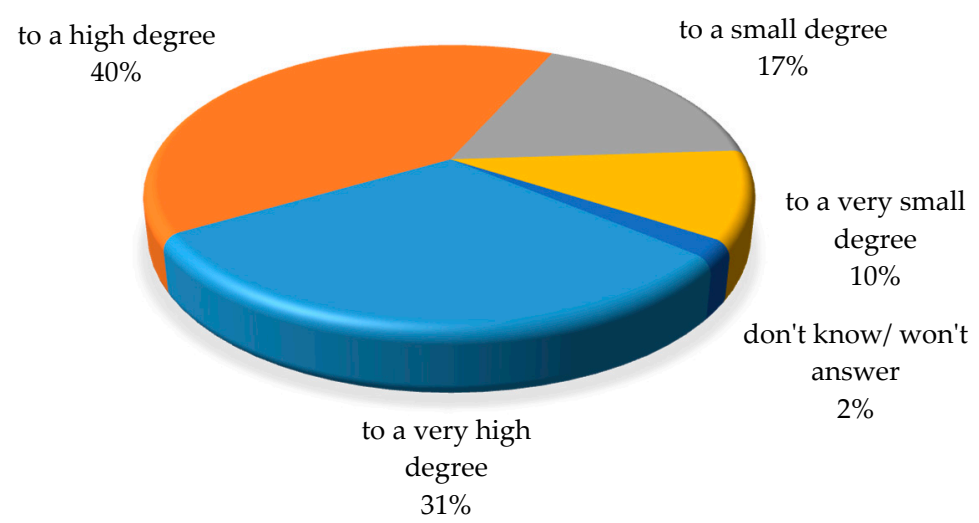

Figure 6. Acceptance of autonomous cars.

Even though there are opinions that the students in the two groups (technical and humanities) share, they also have different perceptions regarding AI sustainable development. In this respect, we have noticed significant differences in the five indicators developed for the AI sustainable development, given that the students pursuing technical studies have a more favorable perception than the humanities students (the analysis was carried out in the same manner, by using the $t$-test). The only indicator that does not show significant differences in perceptions is the one referring to social equity.

\section{Conclusions}

Sustainable agriculture, more ecological production processes, traffic safety, disease and poverty eradication, a better health system, more secure workplaces, more personalized learning, a safer society-all these show the practical social advantages that the AI development could bring in the future. Lately, technology and innovation have led to a large improvement of our life conditions, but at the same time, they have also brought us a lot of concerns.

The development of AI poses a series of existential problems and a great many questions to which we have no answers [24]. At this moment, we do not yet know what humankind will look like in the artificial intelligence age, or how the latter will alter the structure of society. We can, however, extract a series of answers and reactions from those who will become the potential beneficiaries of this technological development. As results show, the population included in the study, namely undergraduate students of Timisoara, manifest a generally positive attitude towards the emergence of $\mathrm{AI}, 58.3 \%$ considering that it will have a positive influence on the society. Most respondents $(28.2 \%)$ claim to be optimistic when thinking about society in the age of artificial intelligence. Nevertheless, the percentage of those confessing to being confused is almost as big.

The Timisoara students who took part in the present survey show a positive attitude concerning autonomous cars: Over $70 \%$ of them would agree to let their family use an autonomous car if they knew that its accident rate is lower than that of the drivers'.

The greatest fears are related to the probability that intelligent devices might destroy humankind (for one third of students) and might replace people in certain activities and jobs.

The disappearance of workplaces is considered by approximately $33.2 \%$ of the respondents to be one of the threats triggered by the AI development. The fields of activity in which the respondents consider that, in the future, the artificial intelligence would be of utmost importance are: The automotive industry 
$(83 \%)$, agriculture $(66.6 \%)$, banking $(64.3 \%)$, parcel delivery and courier services $(56.3 \%)$, public transport $(51.5 \%)$, the military $(51.3 \%)$ and firefighting $(51.3 \%)$.

The use of the artificial intelligence as a means for sustainable development represents a goal: It is our responsibility to constantly assess the direction to which we are heading and to identify the development paths that we want to pursue. At the same time, with the development of the innovations in the AI field, the research on the social impact of these innovations should be financed and the means leading to the society's sustainable development should be found.

As we have observed, there are significant differences in the level of information of the students pursuing technical studies and of the humanities students. The fact that the people taking a degree in technical studies have a wider understanding of the use of the AI devices in activities that should replace human work (as compared to the young people taking a degree in humanities), also comes from the fact that the former are closer to this topic due to their profession.

There are also differences between the male students and the female students regarding the level of information and interest in the topic of artificial intelligence. At the same time, the students following technical studies show a higher level of confidence for the AI sustainable development in the future. The humanities students are more interested in the human value, which they protect, and seem more willing to perceive the disadvantages of the AI development (economic crises, increase in military conflicts, negative effects on human relationships, less jobs for people).

The idea of the sustainable development of the artificial intelligence in the future relies on the extent to which people will familiarize themselves and adapt to it, but also on the manner in which they will feel that they can maintain the control over the practical uses of the artificial intelligence.

As a follow-up to this study, we aim to research the 17 Sustainable Development Goals in detail, in order to get an insight into the way in which the AI development will cater for some social necessities as well as to identify other variables (related not only to background education and gender) that are likely to influence the degree of acceptance of the new technologies.

Author Contributions: All authors contributed equally to this work. All authors have read and approved the final manuscript.

Funding: This research received no external funding.

Acknowledgments: The authors would like to thank their colleagues, who disseminated the questionnaire to their students, and the students, who took the time to fill it in online.

Conflicts of Interest: The authors declare no conflict of interest.

\section{References}

1. Risto, L. Technology as an Enabler of Sustainable Well-Being in the Modern Society; Sitra Studies: Helsinki, Finland, 2015.

2. Choi, J.; Jun, S.; Park, S. A patent analysis for sustainable technology management. Sustainability 2016, 8, 688. [CrossRef]

3. Kim, S.; Jang, D.; Jun, S.; Park, S. A novel forecasting methodology for sustainable management of defense technology. Sustainability 2015, 7, 16720-16736. [CrossRef]

4. Park, S.; Lee, S.; Jun, S. A network analysis model for selecting sustainable technology. Sustainability 2015, 7, 13126-13141. [CrossRef]

5. Osoba, O.A.; Welser, W., IV. An Intelligence in Our Image: The Risks of Bias and Errors in Artificial Intelligence; Rand Corporation: Santa Monica, CA, USA, 2017.

6. Scharre, P. Autonomous Weapons and Operational Risk; Center for a New American Security: Washington, DC, USA, 2016.

7. Nadimpalli, M. Artificial Intelligence Risks and Benefits. Available online: http://www.rroij.com/openaccess / artificial-intelligence-risks-and-benefits-.pdf (accessed on 11 May 2018).

8. McCarthy, J. What Is Artificial Intelligence? Available online: http://www-formal.stanford.edu/jmc/ (accessed on 11 May 2018). 
9. Cambridge Dictionary Britannica. Available online: https://dictionary.cambridge.org/dictionary/english/ artificial-intelligence (accessed on 21 April 2018).

10. The American Heritage ${ }^{\circledR}$ Science Dictionary. Available online: https://ahdictionary.com/ (accessed on 21 April 2018).

11. Artificial Intelligence Innovation Report. 2016. Available online: https://www2.deloitte.com/content/dam/ Deloitte/at/Documents/human-capital/artificial-intelligence-innovation-report.pdf (accessed on 23 April 2018).

12. Gates, B. “A Robot in Every Home”, in Scientific American. Available online: https://www.scientificamerican. com/article/a-robot-in-every-home-2008-02/ (accessed on 25 April 2018).

13. Müller, V.C.; Bostrom, N. Future progress in artificial intelligence: A Survey of Expert Opinion. In Fundamental Issues of Artificial Intelligence; Springer: Berlin, Germany, 2016; pp. 553-571.

14. What Consumers Really Think About AI: A Global Study. Available online: https://www.ciosummits.com/ what-consumers-really-think-about-ai.pdf (accessed on 27 April 2018).

15. Attitudes towards the Impact of Digitization and Automation on Daily Life. 2017. Available online: https:/ /ec. europa.eu/digital-single-market/en/news/attitudes-Towards-impact-digitisation-and-automation-daily-life (accessed on 3 May 2018).

16. Twitter. 2014. Available online: https://twitter.com/elonmusk/status/495759307346952192?lang=en (accessed on 3 May 2018).

17. Kurzweil, R. The Singularity Is Near: When Humans Transcend Biology; Penguin: New York, NY, USA, 2006.

18. Lytras, M.D.; Raghavan, V.; Damiani, E. Big data and data analytics research: From metaphors to value space for collective wisdom in human decision making and smart machines. Int. J. Semantic Web Inf. Syst. 2017, 13, 1-10. [CrossRef]

19. Lytras, M.D.; Visvizi, A. Who Uses Smart City Services and What to Make of It: Toward Interdisciplinary Smart Cities Research. Sustainability 2018, 10, 1998. [CrossRef]

20. Lytras, M.D.; Mathkour, H.I.; Abdalla, H.; Al-Halabi, W.; Yanez-Marquez, C.; Siqueira, S.W.M. Enabling technologies and business infrastructures for next generation social media: Big data, cloud computing, internet of things and virtual reality. J. Univ. Comput. Sci. 2015, 21, 1379-1384.

21. Ordóñez de Pablos, P.; Lytras, M.D. Knowledge Management, Innovation and Big Data: Implications for Sustainability, Policy Making and Competitiveness. Sustainability 2018, 10, 2073. [CrossRef]

22. ITU News Magazine. AI for Social Good How Artificial Intelligence Can Boost Sustainable Development. Available online: https:/ /www.itu.int/en/itunews/Documents/2017/2017-01/2017_ITUNews01-en.pdf (accessed on 15 May 2018).

23. Rifkin, J. The End of Work: The Decline of the Global Labor Force and the Dawn of the Post-Market Era; Putnam Publishing Group: New York, NY, USA, 2015.

24. Bostrom, N. Superintelligence: Paths, Dangers, Strategies, 1st ed.; Oxford University Press, Inc.: New York, NY, USA, 2014.

(C) 2018 by the authors. Licensee MDPI, Basel, Switzerland. This article is an open access article distributed under the terms and conditions of the Creative Commons Attribution (CC BY) license (http:/ / creativecommons.org/licenses/by/4.0/). 